\title{
Modelling the valuesphere and the ecosphere: Integrating the decision makers' perspectives into
} LCA

\author{
Journal Article \\ Author(s): \\ Hofstetter, Patrick; Baumgartner, Thomas; Scholz, Roland W. \\ Publication date: \\ 2000 \\ Permanent link: \\ https://doi.org/10.3929/ethz-b-000423077
}

Rights / license:

In Copyright - Non-Commercial Use Permitted

Originally published in:

The International Journal of Life Cycle Assessment 5(3), https://doi.org/10.1007/BF02978618 


\title{
The MIIM LCA PhD Club
}

\section{Modelling the Valuesphere and the Ecosphere:}

\section{Integrating the Decision Makers' Perspectives into LCA}

\author{
Patrick Hofstetter ${ }^{1,2}$, Thomas Baumgartner ${ }^{2}$, Roland W. Scholz ${ }^{2}$ \\ 'since September 1999: ORISE Research Fellow, National Risk Management Research Laboratory, U.S. EPA, 26W., \\ Martin Luther King Dr., Cincinnati, OH, 45268, USA; hofstetter.patrick@epa.gov \\ ${ }^{2}$ Department of Environmental Sciences, Natural and Social Science Interface (UNS), ETH Zurich, ETH-Zentrum HAD, \\ CH-8092 Zurich; baumgartner@uns.umnw.ethz.ch/scholz@uns.umnw.ethz.ch
}

Corresponding author: Patrick Hofstetter; e-mail: hofstetter.patrick@epa.gov

\section{DOI: http://dx.doi.org/10.1065/lca2000.02.015}

Abstract. Methods for Life Cycle Impact Assessment have to cope with two critical aspects, the uncertainty in values and the (unknown) system behaviour. LCA methodology should cope explicitly with these subjective elements. A structured aggregation procedure is proposed that differentiates between the technosphere and the ecosphere and embeds them in the valuesphere. LCA thus becomes a decision support system that models and combines these three spheres. We introduce three structurally identical types of LCA, each based on one coherent but different set of values. These sets of values can be derived from the Cultural Theory and are labeled as 'egalitarian', 'individualistic', and 'hierarchic'. Within Life Cycle Impact Assessment, a damage oriented assessment model is complemented with both a newly developed precautionary indicator designed to address unknown damage and an indicator for the manageability of environmental damages. The indicators for unknown damage and for manageability complete the set of indicators judged to be relevant by decision makers. The weights given to these indicators are also value-dependent. The framework proposed here answers the criticisms that present LCA methodology does not strictly enough separate subjective from objective elements and that it fails to accurately model environmental impacts.

Keywords: Assessment framework; cultural bias, Cultural Theory; decision support system; ecosphere; known damage; Life Cycle Assessment; Life Cycle Impact Assessment; manageability; perspectives; precautionary principle; uncertainty assessment; unknown damage; value frames; valuesphere

\section{Introduction}

Product-oriented environmental policies have been increasingly adopted by governmental and non-governmental organisations and by industry and its interest associations as well. The need for instruments and tools to support product-oriented decision making has increased correspondingly (VROM, 1994). Environmental Product Life Cycle Assessment (LCA) is one of the environmental instruments considered to be important in the context of product-oriented decision making (SETAC, 1993; ISO, 1997). Nevertheless, LCA's position and its relation to other instruments is still at debate (OECD, 1995; WrisBerG et al., 1998) and the need for its further development has been identified (UDO DE HAES et al., 1997; BaRNTHOUSE et al.; 1997).

According to ISO (1997), LCA consists of four phases that can be followed iteratively: goal and scope definition, inventory analysis, impact assessment, and interpretation. In impact assessment, two main developments can be identified. A first path concerns the update of established methods, e.g., the ecoscarcity method (AHBE et al., 1990; BUWAL, 1998) or the environmental theme approach (HeIJuncs et al., 1992; GUINEE, 1999), the latter being the basis for related developments (e.g., HausCHILD et al., 1998). A second path involves a shift to models that are to predict impacts and damages more accurately. This is done either by making the models more site-dependent (PotTing et al., $1997 /$ $1998)$ or by modelling category indicators that are on an endpoint rather than a midpoint level (KREwITT et al., 1998; GOEDKOOP et al., 1998).

These developments in LCA methodology are explicitly or implicitly driven by two main points of criticism: (1) LCA does not strictly separate the subjective from the objective elements and (2) LCA does not (yet) have an acceptable way to model impacts. These points were especially raised during the standardisation of LCA in ISO 14042 and, e.g., in BARNTHOUSE et al. (1997) and OWENS (1998).

This paper argues that - in contrast to criticism (1) - subjective elements should be integrated into all phases of LCA rather than treated separately, but that the subjective elements have to be organised in a sophisticated manner that acknowledges social science knowledge in particular. The general aim of methodology development in LCA, and therefore also in this paper, should be to find a framework that appropriately copes with both the uncertainty in values and the (unknown) system behaviour.

In order to reorganise the subjective elements, we suggest here to explicitly complement the models for the technosphere and for the ecosphere with a model for the valuesphere. Our 
framework provides a consistent treatment of value judgements and is able to deal with distinct world views. Conceptually we make reference to research on risk perception which shows that different groups vary in their consideration of the different aspects of risk (JUNGERMANN et al., 1993; WEBER et al., 1999). The proposed framework thus allows for an incorporation of the decision makers' value systems into goal and scope definition, inventory analysis, impact assessment and valuation.

Furthermore, we suggest to model environmental damages instead of impact indicators and to complement this information with two additional attributes, one that leads to an indicator for unknown damage and another one that indicates the manageability of the expected damages. Such a broadened modelling framework allows both for a scientifically valid modelling of impacts and provides an extended decision support basis for all types of decision makers.

The presentation of this new framework starts with the introduction and justification of a systems view made up of three spheres. The subsequent sections present the models for the valuesphere and for the ecosphere and their linkage in a decision support system. Finally, some implications of the framework for the decision support and for the inherent shape of LCAs are discussed. We expand on some elements of the approach presented here in four appendices. In this way the busy reader or one familiar with some aspects can read straight through the text. Those not satisfied with the explanations given or curious about a more detailed justification and argumentation can turn to Appendix 1 for the Cultural Theory and Appendices 2 to 4 for a presentation of the indicators for damage assessment, unknown damage and damage manageability.

This paper's focus is on a condensed introduction to this new framework that is applicable to LCA in general. But its special emphasis is on the phase of LCIA. The full specification and quantification of the framework are presented in Hofstetter (1998).

\section{The Decision Maker's Forgotten Value System}

Today's LCA consists of a model of the product system, itself a part of the technosphere, plus a model of the ecosphere, which looks at the fate of the substances and at the potential impacts of the interventions between the product system and the ecosphere. Such a view of the system would be sufficient if (i) there was only one way to describe the product system and isolate it within the technosphere and if (ii) the ecosphere could be described as just one single utility function (as is done usually in utility theory (KEENEY et al., 1976)). However, there are good arguments for the view that both of these conditions cannot be met.

Ad i): The division of the technosphere into distinct product systems is an artifice that not only depends on conventions, e.g., the widely discussed allocation rules, but is driven as well by the aim and the scope of the decision support and by the decision maker's view on, e.g., structural changes within the technosphere.

Ad ii): The utility - as well as dis-utility, which is in fact the better term to describe environmental damages - of the ecosphere is multidimensional and should be described by a set of criteria. Utility is a social construct that cannot be determined by natural science methods, i.e., it is a normative step to define what is 'environment' and which changes in it are considered to be adverse. Thus, adverse impacts on the ecosphere are a human construct as well.

Consequently, an additional sphere has to be introduced to represent the decision makers' views and the human actor that "constructs" the model of the ecosphere. Fig. 1 symbolises the relative position of the three spheres. The technosphere is assumed to be a part of the ecosphere in the sense that as an industrial metabolism (AYres et al., 1994) it is in intense interaction with the ecosphere. The ecosphere and the technosphere are both embedded in the valuesphere, i.e., their characterisation and modelling are assumed to depend on the view with which they are perceived.

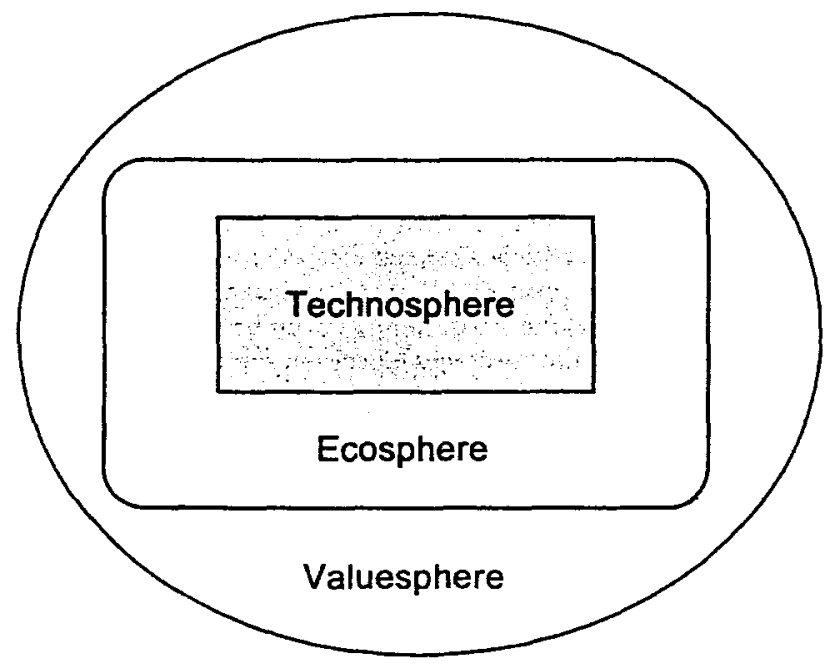

Fig. 1: The three spheres to be modelled and linked in LCA

The constructivistic view behind these models of the three spheres also forms the backbone of the framework presented here. It represents a radical departure from the strategy usually chosen as response to the first main criticism of LCA (see introduction), namely to describe the ecosphere and the technosphere with objective elements only. In this alternative approach, it is the subjective elements that determine the view of the eco- and of the technosphere and shape the models representing them. However, the new framework unites all the subjective elements by assuming that they together constitute the valuesphere and that their determination follows certain rules. Therefore, LCA could be described as the art of modelling and of combining the valuesphere, the ecosphere, and the technosphere.

\section{Modelling the Valuesphere by Cultural Theory}

In line with Fig. 1 we start the modelling with the most encompassing sphere, the valuesphere. We begin with the level of world views, then define the elements of the environment that are to be protected (because they are valued), and finally identify the causal factors within the techno- 
sphere. This might be called a top-down procedure (see, e.g., HofSTETTER, 1999). Two motivations to explicitly address all value judgements by defining the valuesphere are that it ensures that value judgements within all phases of LCA will form a coherent whole and that they represent the values held or represented by the decision maker(s).

Two tracks can be followed to determine the value sets: A) It can be argued that the environment is a collective good. Therefore, societal values expressed, e.g., in environmental policy, should constitute the valuesphere.

B) All the value sets of the presently living six billion individuals should be taken as a basis. But for reasons of practicability only a representative subset of distinct value sets can actually be used.

Track (A) is not really compatible with the motivations for modelling the valuesphere because societal values do not form a coherent whole, i.e., environmental policy is a historical patchwork of single policy decisions and its current make up lacks the wanted consistency. Further, it would compel decision makers to adhere to official views, which may well differ from their own. Such a congruence is unlikely as long as the use of LCA is voluntary. Under track (B), LCA could be based on consistent but distinct pictures of how the desired future should look like. This approach therefore encourages merhodology developers and decision makers to look at both the techno- and the ecosphere from different angles and this will enhance their understanding of the system at stake (and of the views of others). And finally, it is possible to convert a track (B) approach to a track (A) one and this makes track (B) the more flexible one.

To derive a model of the valuesphere from normative concepts such as sustainability would be a variation on track (A) although this approach would avoid some of the disadvantages identified above (VoLKWEIN et al., 1996). At a closer look, however, sustainability does not provide a sufficiently crisp normative reference system for a specific valuesphere. Sustainability only requires development of the socio-environment in an inter-generationally just and equitable way. Whether a society will focus on certain technologies or on specific cultural habits remains open, at least within a wide range.

The subset of distinct value sets required for track (B) could be established through an (expensive) representative empirical study of the world population. However, this would ignore the large body of knowledge that has been already acquired with respect to societal values. Numerous scientists have been engaged in the collection of data and the establishment of theories and heuristics that validly describe and classify societal lifestyles and value systems:

(i) anthropologists and scientists of religion characterise different cultures,

(ii) psychologists and sociologists classify different world views, attitudes and values in and between individuals, and (iii) social scientists and marketing researchers portray lifestyles and consumption patterns.

From the perspective taken in this paper, the following criteria should be fulfilled by a heuristic or a framework that can be used as a qualitative model of the valuesphere:
- The decision makers' value judgements about the technosphere and the ecosphere should be addressed directly or indirectly or should be at least derivable with the heuristic.

- The heuristic should allow classifying the decision makers' perceptions of the environment and of his/her assumptions about the dynamics and the sensitivity of the environment.

- All the existing world views should be covered by a small number of distinct views and thus increase the practicability of the approach.

- Due to the constraints that (socio-)economic and situational factors put ón overt behaviour, lifestyles and consumption patterns, the framework (i) is considered as a heuristic at the levels of values, world views, or cultures which, however, (ii) reveals truly held behavioural orientations, dispositions and aspirations.

- The heuristic should be empirically valid, easy to communicate to decision makers, and it would be advantageous if it were already well-known.

Hofstetter (1998) has reviewed a large number of heuristics and theoretical approaches, none of which fulfils all of these criteria. However, Cultural Theory (CT) meets the first four criteria sufficiently well. It can be communicated to decision makers and it gets increasingly better known in the environmental sciences (see Appendix 1, p. 170, for a further attempt to make it better known). Its empirical validity is still rather low and does not yet satisfy (all) the rigid criteria psychologists usually require of personality or attitude tests. Recent empirical studies acknowledge that the best way to validate it still has to be found (Marris et al., 1998; BRENOT et al., 1998). But the explanatory power of CT has been found acceptably good in a broad field of applications and it is used as well in other environmental instruments such as integrated assessment (VAN ASSELT et al., 1996a/b). Hofstetter (1998:70f) discusses a selection of related typologies that could be used instead of CT. Up to now there is no other approach available which is superior for the task at hand, i.e., to integrate the different types of value systems into LCA.

The CT community has developed the grid-group characteristics and the myths of nature introduced in Fig. 5 and 6 (see Appendix 1, p. 170) and in the course of many applications a long list of attributes assignable to the archetypes has been identified. Table 1 provides a selection of those attributes that may prove relevant for the modelling in LCA of the ecosphere and of the technosphere. The 'perception of time' and its consequences for the 'temporal survival dilemma' and for the 'discounting' are relevant when temporal system boundaries are at stake; 'criteria' is relevant when the degree of evidence needed to establish a relationship is defined. And 'trust' or 'method for applying model of consent' is helpful when a decision support instrument has to be fitted into a decision process. Table 1 can be seen as a scenario generator where only one combination of the attributes is compatible with each archetype. This information on the value judgements that are compatible with each other is the added value of $\mathrm{CT}$ as a model of the valuesphere. It considerably reduces the uncertainty in value choices. 
Table 1: World views, attitudes, management styles and characteristics of the four archetypes, (1) JAGER et al. (1997), (2) RAYNER (1991), (3) SCHWARZ et al. (1990:66f), (4) compiled by van Asselt et al. (1995) out of THOMPSOn et al. (1990), (5) THOMpson et al. (1998) (see Hofstetter, 1998:55f for a full list).

\begin{tabular}{|c|c|c|c|c|}
\hline $\begin{array}{r}\text { Archetypes } \rightarrow \\
\text { Attribute categories } \downarrow\end{array}$ & Hierarchist & Egalitarian & Individualist & Fatalist \\
\hline Myth of nature (4) & Nature is perverse/tolerant & Nature is fragile & Nature is benign & Nature is capricious \\
\hline Perception of time (3) & $\begin{array}{l}\text { Balanced distinction bet- } \\
\text { ween short and long term }\end{array}$ & $\begin{array}{l}\text { Long term dominates } \\
\text { short term }\end{array}$ & \begin{tabular}{|l|}
$\begin{array}{l}\text { Short term dominates long } \\
\text { term }\end{array}$ \\
\end{tabular} & $\begin{array}{l}\text { Involuntary myopia } \\
\text { (short--sightedness) }\end{array}$ \\
\hline Scope of knowiedge (3) & $\begin{array}{l}\text { Almost complete and } \\
\text { organised }\end{array}$ & Imperfect but holistic & Sufficient and timely & Irrelevant \\
\hline Benefit-risk dilemma (1) & Benefits versus risks & Risks & Benefits & Ad hoc \\
\hline Spatial survival dilemma (1) & $\begin{array}{l}\text { Local versus global } \\
\text { outcomes }\end{array}$ & Global & Local & Ad hoc \\
\hline Social survival dilemma (1) & $\begin{array}{l}\text { Individual versus collective } \\
\text { outcomes }\end{array}$ & Collective & Individual & Individual \\
\hline Procedures applied (2) & Rules & Ethical standards & Skills & - \\
\hline Criteria (2) & Evidence & Argument & Experience & - \\
\hline $\begin{array}{l}\text { Temporal survival dilemma } \\
\text { (1) }\end{array}$ & $\begin{array}{l}\text { Present versus future } \\
\text { outcomes }\end{array}$ & Future & Present & Ad hoc \\
\hline Trust (2) & Procedures & Participation & Successful individuals & - \\
\hline View of resources (3) & Scarce & Depleting & Abundant & Lottery \\
\hline Management style (4) & Control & Preventive & Adaptive & - \\
\hline Discounting (5) & Technical standard & Zero/negative & Diverse/high & - \\
\hline $\begin{array}{l}\text { Search and change } \\
\text { behaviour (3) }\end{array}$ & $\begin{array}{l}\text { High on search; low in } \\
\text { (internal) change }\end{array}$ & $\begin{array}{l}\text { High on search: high } \\
\text { on (external) change }\end{array}$ & $\begin{array}{l}\text { 'Satisficing'; enough } \\
\text { search for enough change }\end{array}$ & $\begin{array}{l}\text { No search; fatalistic } \\
\text { acceptance of change }\end{array}$ \\
\hline $\begin{array}{l}\text { Method for applying model } \\
\text { of consent (3) }\end{array}$ & $\begin{array}{l}\text { Natural (or other ideal) } \\
\text { standards }\end{array}$ & $\begin{array}{l}\text { Expressed } \\
\text { preferences }\end{array}$ & Revealed preferences & - \\
\hline Attitude towards risk (4) & Risk-accepting & Risk-aversive & Risk-seeking & - \\
\hline
\end{tabular}

From Appendix 1 (p.170) and from the attributes in Table 1, one can deduce that "fatalists" will not ask for LCAs to support decisions and that they take no active role in decision making. "Hermits" withdraw from social involvement altogether (but are a very small share of present societies). Therefore, only the three perspectives active in social decision making, namely "hierarchy", "individualism" and "egalitarianism", are used to model the valuesphere and shapes of LCA.

This choice is backed by Beentjes et al. (1995) and Mengel Jørgensen (1996) who have shown that these three perspectives are dominant within stakeholder and interest groups. They have shown too that, e.g., not all environmentalists adhere to egalitarian principles and that all perspectives are to be found within private business.

The modelling framework presented here for the valuesphere asks for three different types of LCA, each one compatible with one of the active cultural perspectives. To operationalise this link of the three spheres, one has to choose for each specific judgement at hand the most plausible attributes from those listed in Table 1 and transpose them to the value judgements within each of these three LCA types. These translations will have to be empirically validated once the whole system of LCA has been described and modelled in terms of CT.

\section{Modelling the Ecosphere by Known and Unknown Damages and by its Manageability}

Among the many possible ways to model the ecosphere, we are interested here in a model that helps to assess the magnitude and the severity of environmental impacts due to a change in the volume of production or due to a change of technology in a product system. This purpose introduces a hierarchy into the ecosphere that is best described by causeeffect relationships. The causes are defined at the level of environmental interventions, i.e., at the interface between the technosphere and the ecosphere. The definition of effects and the way to model the cause-effect relationships are less trivial and will be discussed here in more detail.

One criticism of LCA, as has been pointed our, is that so far the modelling of impacts has not been done in an acceptable manner. One reason is that place and time of environmental interventions remain mostly unreported in the inventory table. It is therefore impossible to consider, e.g., variations in ecosystem sensitivity, population density or actual concentrations and the surpassing of thresholds. This aspect of modelling will not be addressed here further because we assume that neither place nor time of release is known, be it because both are unknown or because the inventory table just does not provide this information. A second reason will be addressed here, however: the damageoriented modelling makes explicit which environmental changes are considered as damages and its results address actual damages rather than phantoms. In fact, this is a shortcoming of the internationally well received and accepted environmental theme approach (Heijungs et al., 1992; SETAC, 1993). It suggests category indicators that are modelled on a midpoint level without modelling explicitly adverse effects on endpoint levels.

The damage-approach starts by characterising the ecosphere with a small number of safeguard subjects. Only changes to 
these safeguard subjects are judged as damages (or benefits). This approach to LCIA was first suggested by STEEN et al. (1992), adapted by GoEDKOOP (1995), substantiated by MULLER-WENK (1997) and operationalised by GOEDKOOP et al. (1998/1999). The definition of safeguard subjects and of those changes that are considered to damage them are both explicit value judgements. These judgements should be made in accordance with the other value judgements necessary during an LCA and should be recorded in the goal and scope definition.

Appendix 2 (p. 172) provides a short summary of the methodology of damage assessment. The damage approach implies:

- that the ecosphere can be described as a hierarchic structure retracing the impact-pathways from changes to the safeguard subjects backwards to the environmental interventions

- a static representation of the ecosphere where small marginal changes are modelled without considering dynamic feedback mechanisms that could include interactions between the safeguard subjects, and

- that one accepts that only known and quantifiable causeeffect relationships are included.

This last point is a serious shortcoming of the approach but it just mirrors the state of knowledge and is anyway immanent to all other tools making use of impact pathways. The dilemma of the environmental sciences in describing and quantifying causal relationships is that, on the one hand, only (laboratory) experiments allow proof of causation. But these results cannot be transferred to real conditions. Epidemiological studies that gather the information from real conditions, on the other hand, are unable to provide proof of causation. They just quantify an association between two factors for which there is limited evidence of causality. It is decision makers and not scientists that have to decide on the degree of evidence they consider to be sufficient to take action.

Adams (1995) suggests to group risks into three types:

(i) directly perceivable risks like, e.g., car accidents,

(ii) risks perceived through science like, e.g., cancer from smoking, and

(iii) virtual risks which scientists do not know about or cannot agree upon like, e.g., genetically modified organisms and non-ionising radiation. He argues that this third type of risks is normally not considered in risk assessment, but that the different archetypes perceive their relevance very differently. These three types can be interpreted as three levels of a decreasing degree of evidence on causality.

Fischhoff et al. (1978) and Marris et al. (1998) have found that everybody but risk analysts use a rich definition of risk. They find that everyone else adds to the total amount of damage such criteria as: voluntariness of risk, immediacy of effect, knowledge about risk by exposed persons, knowledge about risk by science, chronic versus catastrophic risk, common dread, severity of consequences, control over risk, newness, harm to future generations, and unequal distribution of risk and benefit.

A framework for the modelling of the ecosphere should therefore not just permit the modelling of environmental damages but should also take into account the variety of deci- sion makers' needs for decision support. We suggest three submodels to provide the relevant information for all types of decision makers ( $\rightarrow$ Fig. 2 ):

Submodel 1: Damage assessment based on known causalities (see Appendix 2, p. 172)

The modelling of known damages is based on state-of-theart methods and on knowledge from all the sciences concerned. It is indicated by the light grey oval in Fig. 2 and is based on a representation of the environment by safeguard subjects.

Submodel 2: Unknown damages or unknown causalities (see Appendix 3, p. 173)

The dark grey unevenly shaped area symbolises what ADAMS (1995) calls virtual risks or what studies on risk perception call degree of knowledge about risk, common dread, and newness. It is designed as a proxy indicator that can be used to represent a quantification of the precautionary principle and will be named 'unknown damage'.

Submodel 3: Manageability (see Appendix 4, p. 174)

The dynamic dimension of submodel (1) and information on the control over risk have so far been lacking in LCA and are added explicitly in this third submodel. This so-called 'manageability' is visualised with bold arrows in Fig. 2 and presupposes the normative definition of a level of acceptable or target damage.

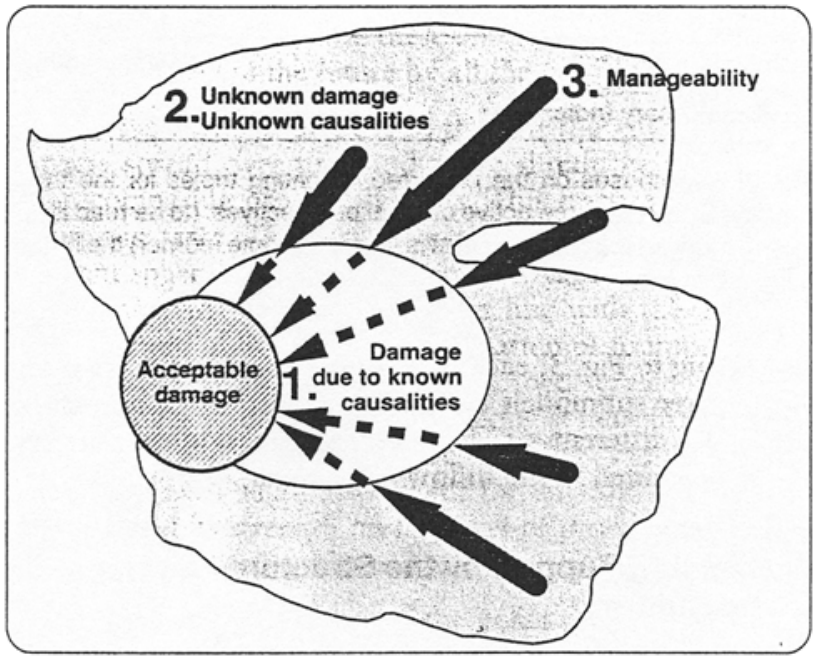

Fig. 2: The modelling framework for the ecosphere

This framework for modelling the ecosphere explicitly addresses three different types of system characteristics that decision makers consider to be relevant. Appendices 2 to 4 suggest new ways to operationalise them.

The discussion in Appendix 4 suggests that in LCA there are no methods in use that are based on an explicit modelling of manageability alone. However, models based on either damage assessment (STEEN et al., 1992; GoedKOOP et al., 1999) or on proxies for unknown damages (SCHMIDT-BLEEK, 1993) have been used already for LCIA. This lends support to the strategy to include both dimensions instead of controversially discussing the best approach. 
Fig. 3 illustrates a plausible hypothesis about the unequal importance assigned to these submodels by the three archetypes of CT. 'Egalitarians' give high priority to the precautionary principle because it mirrors the unknown damage and they believe more in the holistic models than the simplistic hierarchic modelling used for the assessment of known damage. 'Individualists' consider estimates of known damage to be the most reliable source for information on which to base their decisions on investments. 'Hierarchists' look out for a balanced consideration of information on damages (believing in science), the precautionary principle (as a possibility to prevent disasters in the future) and manageability (control being a strong skill of 'hierarchists').

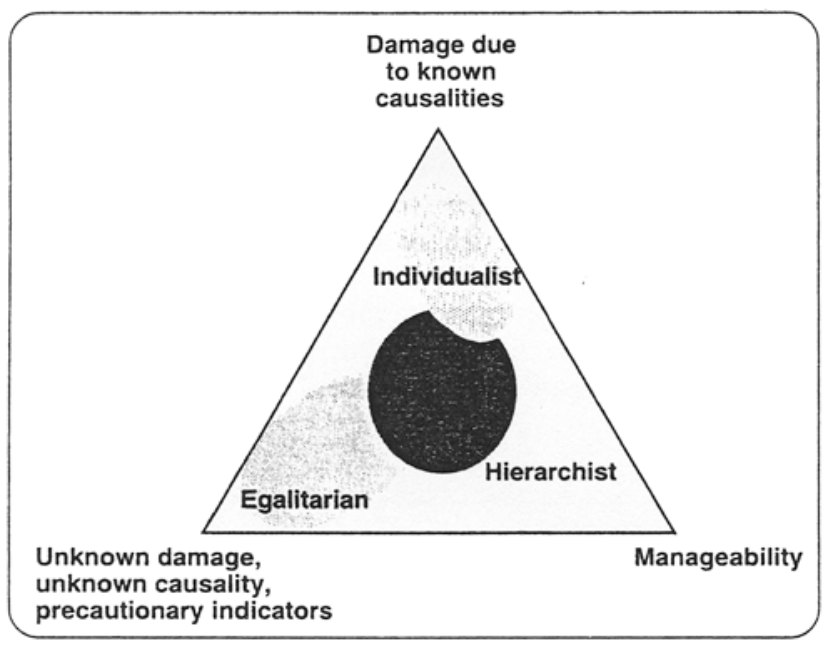

Fig. 3: Hypotheses on the preferred weighting triples for the three submodels by the three active cultural perspectives. (to be read like a mixing triangle: the closer a point is to one attribute (corner) the higher is the attribute's weight)

According to Fig. 3, each perspective considers at least one of the three submodels as important. But for each perspective it is a different set. The step to a decision support system is presented in the following section.

\section{Decision Support by the Structured Aggregation Procedure}

The purpose of this section and especially of Fig. 4 is to show how the elements introduced so far are put together to form a decision support system. The following remarks may be important for the understanding of Fig. 4:

- Modelling the valuesphere leads to three coherent but distinct sets of value choices. These sets are symbolised in Fig. 4 by the three layers labelled with the names of the cultural perspectives. Consequently, there are three different LCAs.

- Although there is a different LCA for each of the three perspectives, their structures are kept identical. This feature is important because it enables decision makers to more easily understand all three types of LCA. They will consequently be able to understand the differences in the outcome more easily.
- This article does not elaborate on the model of the technosphere and its links with the valuesphere. The inventory table and the proxy for unknown damage are at the present time identical for all three LCAs. However, Hofstetter (1998:368f) provides examples for value choices in the inventory analysis (allocation rules and leakage from land-filling) and discusses them in terms of CT. The full development of this approach appears to be feasible.

- So far, the submodels for unknown damage and for manageability have been developed only for emissions. The damage assessment presented in Goedkoop et al. (1999) includes in addition land use changes and use of highly concentrated resources.

- The manageability factor is understood as a factor modifying the assessed damage. The indices for manageability and for known damage are therefore combined and called 'manageability adjusted damages' (MADs). The combination can be made by a simple weighting which, however, depends on the cultural perspectives $(\rightarrow$ Fig. 3 ). These MADs have to be calculated separately for each safeguard subject.

- Finally, in the case of product comparisons, we suggest to present the information on the three MADs and on the unknown damage in the mixing tetrahedron (HoFSTETTER et al., 2000). Each point in the tetrahedron represents a weighting quadruple of the entities indicated by the terms at its corners. The four weights in the weighting quadruple add up to 1 . When comparing two product alternatives through an LCA, one calculates the four indicator values for both alternatives. The space

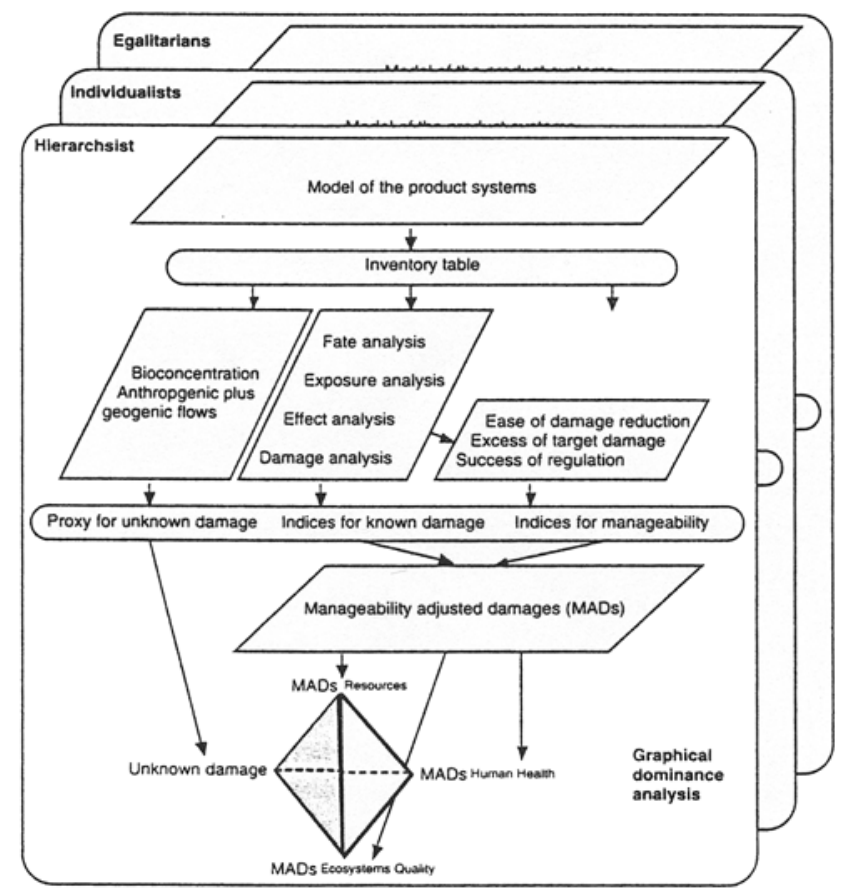

Fig. 4: The structured aggregation procedure with a final dominance analysis (MADs = manageability adjusted damages) 
within the tetrahedron containing all weighting quadruples with a total eco-index better than the one of competing alternatives can be coloured. This parameterisation of the result demonstrates to the decision maker within which range of weights an alternative continues to score best. This dispenses one from the need to make point estimates for the weights. The exact outline of the preferred weighting space is again assumed to depend on the cultural perspective adopted by each decision maker. An empirical study with LCA experts confirms the wide range of preferences held by individuals (METTIER, 1999).

During the development of the framework, CT has shown its usefulness as a tool to model the valuesphere. We suggest that the framework proposed here is complemented by a model for the technosphere and by an operationalisation for the ecosphere. In such a theory-driven operationalisation of the framework, its early validation by decision makers will be of the highest priority. Such a testing may change the shape of the elements proposed here, making some of them obsolete and possibly revealing the need for new elements.

\section{Facilitating Decision Support}

One of the claims of this paper is that the new framework will help to cope with the uncertainty in values. The coherent modelling of values fulfils this claim because it provides additional information on which judgements are consistent and compatible with a given world view. The possible range of values for the eco-index, the aggregate of the four indices presented in the tetrahedron $(\rightarrow$ Fig. 4 ), is already reduced even if no choice among the perspectives is made. The variance is further reduced with the use of the information on the preferred perspective. Variance reduction is one of the technical reasons to develop world-view dependent LCAs.

The considerable reduction in uncertainty if information on the preferred perspective is available will be even pushed further in the core when, e.g., the ranking order of product alternatives is the same for all cultural perspectives. We do not have the experience so far to estimate the probability that such a similarity in outcome will occur. But we believe this may occur in many cases. However, even if the ranking of alternatives depends on the chosen perspective we still have gained a very valuable information, namely that the world view does matter for the decision at hand!

In such instances, decision makers could base their decision on one or the other perspective in full awareness of the partiality of their choice. Or they could decide to emphasise other criteria instead. This apparent flexibility may be seen as a disadvantage of the framework. We are convinced it is not. Firstly, we think that decision makers are prepared to opt for one perspective as much as citizens do when they elect their representatives where they have to select one of the parties, this being another manifestation of (political) perspectives. Secondly, in the case of group decision making, it becomes obvious in such a situation that it is not the further discussion of technical points that will bring a solution but that there is a value debate at stage. At this point, a technical instrument such as LCA can provide the basis for applying discursive methods of conflict resolution.

Another hitherto overlooked aspect may lead to a robust decision support system. It has so far been assumed that the indices produced by this approach to LCA are independent of each other and do not correlate. However, Hofstetter et al. (2000) show that within a product group the correlation could be high indeed. The immediate implication is that the ranking of alternatives is rarely dependent on the weighting of the indices and therefore robust. A further implication, relevant for methodology developers, is that such a high correlation may be the starting point for the development of reliable streamlined methods.

\section{Does LCA Fit Best with Egalitarianism, Individualism or Hierarchy?}

It is not by chance that this question is put at the end of this article. If LCA as an instrument fits better with one of the perspectives than the others, it would have been enough to develop a framework just for that one.

However, Mengel Jorgensen (1996) has argued that theoretically all three active perspectives have a very positive attitude towards LCA (although the commitment depends on the stakeholder group they belong to (see HoFsTETTER (1998:76f) for a summary table). This generally positive attitude towards LCA justifies the approach developed here that LCA, one way or another, has to cope with these different value orientations if it is to be used in the future by all the perspectives.

One of the features of LCA is that all the environmental impacts spread over time and place should be considered when comparing product systems. This feature has a clear egalitarian taste. The very reductionistic modelling of the different spheres and the inevitable hierarchical structuring in current LCA practice is more in line with the needs of hierarchy and individualism. LCAs attempt to improve the eco-efficiency at an externally prescribed service level and its positioning at the micro level, looking at marginal changes alone, is in line with a tool preferred by 'individualists'. The use of LCA as an instrument for environmental management and its strength on the level of product policy are elements preferred by hierarchy.

These few arguments support the belief that LCA, even in its present shape and perception, will both not be used by and does not incorporate one perspective alone. This may well be one of the reasons why the debate on LCA methodology and application is much more heated and controver sial than is known from other environmental decision support tools.

\section{Conclusions}

The purpose for the development of the framework presented here is the need in LCA to cope both with the uncertainty in values and with the (unknown) system behaviour. It can be seen as an answer to the criticism that present LCA methodology does not separate strictly enough subjective from objective elements and fails to accurarely model environmental impacts. The models of the three spheres pre- 
sented here and that are operationalised in the form of a structured approach answer this criticism by:

(i) introducing a model of the valuesphere which makes it possible to deal with the uncertainty of values but also reveals the need to integrate into LCA both the subjective and the objective elements. Cultural Theory has been identified as a useful heuristic that presently fits best as a basis for the modelling of the valuesphere. Its applicability in the context of LCA has been demonstrated.

(ii) exploring an impact assessment procedure that models up to the adverse change of normatively defined safeguard subjects - called damage assessment. This type of damage assessment has now become one path of methodology development in LCIA and is in accordance with ISO. It is an artempt to a more accurate modelling of impacts and it will facilitate or even render unnecessary the step of valuation in LCIA.

(iii) supplementing the damage assessment with submodels for the manageability of impacts and for unknown damages. Presently missing elements, such as the dynamic aspects of environmental damage and the claim that LCA should serve as a precautionary instrument as well, are added by the new developments presented here.

The framework presented here has served as a basis for the newly released Eco-Indicator'99 method for LCIA (GOEDKOOP et al., 1999) that includes not only a worked-out procedure for damage assessment but makes use of the concept of the three spheres as well. This means that Culcural Theory has been chosen to model the value judgements and three distinct types of Eco-indicators'99 are established and will be implemented in commercial LCA software.

The special feature of the framework presented here is the explicitness of many of the elements that have so far remained hidden in LCA. Cultural Theory is one of these elements and it puts the debate on value judgements in LCA squarely on the table. Other important elements are the impact pathway analysis that enables impact modelling to draw on the best available methods from all the sciences concerned and the explicit modelling of damage attributes. The whole structure of the framework is an attempt to make LCA receptive for contributions from natural, social, and technical sciences.

The new framework proposed here may be a prime candidate around which to organise the scientific debate and the joint framework development in LCA. The transparent and robust decision support that is expected to result from this work will improve the credibility of LCA as a decision support instrument and may lead to new powerful streamlined methods. In addition to these implications the new framework has for the structure of LCA, it also will make sure that decision makers will have to be either explicit on their value judgements or will at best become aware of the multiple styles of LCAs this approach implies.

The framework is not yet operationalised for all the environmental problems but has a strong focus on emissions. The model of the technosphere has not been addressed at all here. And the application of the model to the valuesphere is relying on the interpretation of a theory which is in need to be validated by performing empirical studies. These caveats define the next steps for future research. Actual applications of the proposed framework in decision support will hopefully reveal those adjustments to the present framework that are needed to make LCA even more effective.

Acknowledgements. The underlying research has profited from a number of research projects that were financed by the Swiss Priority Programme Environment (Swiss Science Foundation), the DaimlerBenz $A G$, and the research fund of the Swiss electricity utilities (PSEL). A full list of colleagues that have supported these developments (many thanks) can be found in Hotstetter (1998), which is the source for this article.

\section{References}

ADAMS, J. (1995): Risk. UCL Press, London

Ahbe, St.; Braunschweig, A.; Muller-Wenk, R. (1990): Methodik für Ökobilanzen auf der Basis ökologischer Optimierung. Schriftenreihe Umwelt Nr.133, Bundesamt für Umwelt, Wald und Landschaft (BUWAL), Bern

Asselt van, M.; Rotmans J.; den Elzen, M.; Hilderink, H. (1995): Uncertainty in Integrated Assessment Modelling; a Cultural Perspective-based Approach. GLOBO Report Series No.9, RIVM Report No. 461502009, Bilthoven

Asselt VAN, M.B.A.; Beusen, A.H.W.; Hilderink, H.B.M. (1996a): Uncertainty in Integrated Assessment: A Social Scientific Perspective. Environmental Modelling and Assessment 1:71-90

Asselt van, M.B.A.; Rotmans, J. (1996b): Uncertainty in Perspective. Global Environmental Change 6 (2): 121-57

AYres, R.U.; SOMONIS, U.E. (Eds.) (1994): Industrial metabolism: restructuring for sustainable development. United Nations University Press, Tokyo

Barnthouse, L.; Fava, J.; Humphreys, K.; Hunt, R. et al. (1997): Life-Cycle Impact Assessment: The State-of-the-Art. Report of the SETAC North American Workgroup on Life Cycle Impact Assessment, Pensacola

BeentJes, C.; Wrisberg, N.; Ywema, P.E. (1995): The Social Value of Life Cycle Assessment. financed by SPOLD Brussels, Draft

BerG, M.; SCHeringer, M. (1994): Problems in Environmental Risk Assessment and the Need for Proxy Measures. Fresenius Environmental Bulletin $3(8)$ : 487-92

Brenot, J.; Bonnefous, S.; Marris, C. (1998): Testing the Cultural Theory of Risk in France. Risk Analysis, Vol. 18, No.6, 729-739

BUWAL (1998): Methode der ökologischen Knappheit - Ökofaktoren 1997. Schriftenreihe Umwelt Nr.297, OBU/BUWAL, Bern

Douglas, M. (1982): Cultural Bias, in Douglas M. (ed.), In the Active Voice. Routledge and Kegan Paul, London

Douglas, M.; WiLDAVSKY, A. (1982): Risk and Culture; An Essay on the Selection of Technological and Environmental Dangers. Berkley

EXTERnE (1995): Externalities of Energy. European Commission EUR 16520 EN, Volume 1-6, Luxembourg

FisChHOFF, B.; SLOVIC, P.; LiCHTENSTEIN, S.; READ, S.; COMBS, B. (1978): How Safe is Safe Enough? A Psychometric Study of Attitudes towards Technological Risks and Benefits. Policy Sciences 9: 127-52

FrischKnecht, R.; Braunschweig, A.; Hofstetter, P.; Suter, P. (2000): Human Health Damages due to Ionising Radiation in Life Cycle Impact Assessment. to be published in Environmental Impact Assessment Review, 2

GoedKoOP, M. (1995): The Eco-indicator 95. Final Report and 
Manual for Designers, Amersfoort

Goedkoop, M.; Hofstetter P.; Muller-Wenk, R.; Spriensma, R. (1998): The Eco-Indicator' 98 Explained. The International Journal on Life Cycle Assessment 6 (3) 352-360

GOEDKOOP, M.; SPRIENSMA, R. (1999): The Eco-indicator'99, A damage-oriented method for Life Cycle Impact Assessment. VROM, Den Haag

GUINEE, J. (Ed.) (1999): Life Cycle Assessment in environmental policy. Update of LCA methodology Guide \& Background documents of 1992 by Heijungs, R. et al., Draft version, http:// www.leidenuniv.nl/interfac/ $\mathrm{cml} / \mathrm{lca} 2$

HAUSCHILD, M.; WENZEL, M. (1998): Environmental assessment of products. Part 2, scientific background, Chapman \& Hall, Cambridge

Heijungs, R.; Guinee, J.B.; Huppes, G.; Lankreijer, R.M.; Udo DE Haes, H.A.; Wegener SleeswiJk, A.; Anseis, A.M.M.; Eggels, P.G.; van Diun, R.; DE Goede, H.P. (1992): Environmental Life Cycle Assessment of Products; Backgrounds \& Guide. Leiden

Hofstetter, P. (1999): Top - Down; Arguments for a Goal-Oriented Assessment Structure. Global LCA Village, http://www. ecomed.de/journals, ETH Zurich

Hofstetter, P.; Braunschweig, A.; Mettier, Th.; Mueller-Wenk, R.; TIETJE, O. (2000): Dominance Analysis in the Mixing Triangle: Graphical Decision Support for Comparisons with LCA. Journal of Industrial Ecology (in press)

Hofstetter, P. (1998): Perspectives in Life Cycle Impact Assessment; A structured approach to combine models of the technosphere, ecosphere, and valuesphere. Kluwer Academic Publishers, Boston

HollinG, C.S. (1977): Myths of Ecology and Energy, in Proceedings of the Symposium on Future Strategies for Energy Development. Oak Ridge pp.36-49

Holuing, C.S. (1986): The Resilience of Terrestrial Ecosystems: Local Surprise and Global Change. in Clark, W.C.; Munn, R.E. (Eds.), Sustainable Development of the Biosphere. Cambridge University Press, Cambridge

IFIAS (1974): Energy Analysis Workshop on Methodology and Conventions. International Federation of Institutes for Advanced Study. Guldsmedshyttan, Sweden

ISO (1997): Environmental Management - Life Cycle Assessment Principles and Guidelines. EN ISO 14040, Brussels

Jager, W.; VAN Asselt, M.B.A.; Rotmans, J.; Vlek, C.A.J.; Costerman BoodT, P. (1997): Consumer Behaviour; A Modelling Perspective in the Context of Integrated Assessment of Global Change. Globo Report Series No.17, RIVM Report No.461502017, Bilthoven

JungermanN, H.; SLovic, P. (1993): Charakteristiken individueller Risikowahrnehmung. in Bayerische Rück (Hrsg.), Risiko ist ein Konstrukt. Knesebeck Verlag, 89-107

KeEneY, R.L.; RalfFA, H. (1976): Decisions with Multiple Objectives: Preferences and Value Tradeoffs, New York

Kortman, J.G.M.; Lindeijer, E.W.; Sas, H.; Sprengers, M. (1994): Towards a Single Indicator for Emissions - an Exercise in Aggregating Environmental Effects. IDES Amsterdam

KREWTTT, W.; MAYERHOFer, P.; TRUKENMÜLleR, A.; FrIEDRUCH, R. (1998): Application of the impact pathway analysis in the context of LCA; The long way from burden to impact. Int. J. LCA 3 (2) 86-94

LindejJer, E. (1994): The Valuation within LCA: Aim, Criteria and Procedure. in Udo de Haes, H.A.; SChaltegger, S.; Hofstetter, P. (Eds.), First Working Document on Life-Cycle Impact Assessment Methodology. Workshop held at ETH Zurich from July 8 9, 1994 pp.163-170

Marris, C.; LANGFord, I.H.; O'RIORdan, T. (1998): A Quantitative Test of the Cultural Theory of Risk Perceptions: Comparison with the Psychometric Paradigm. Risk Analysis, Vol. 18, No.5, 635647
Mengel Jørgensen, A.-M. (1996): LCA Stakeholders and Weighing of Environmental Problems; a Theoretical Approach to Differing Valuation Criteria. Amsterdam

MetTIER, TH. (1999): Der Vergleich von Schutzgütern - Ausgewählte Resultate einer Panelbefragung. in HofSTETTER, P.; METTIER, TH.; TIETJE, O. (Eds.), Ansätze zum Vergleich von Umweltschäden. 9. Diskussionsforum Ökobilanzen, UNS-ETH Zürich, ISBN 3906734-06-4

MÜlLER-Wenk, R. (1997): Safeguard Subjects and Damage Functions as Core Elements of Life-Cycle Impact Assessment. IWÖDiskussionsbeitrag Nr.42, St. Gallen

Murray, CH.J.L.; Lopez, A.D. (Eds.) (1996): The Global Burden of Disease, Volume I of Global Burden of Disease and Injury Series. WHO / Harvard School of Public Health/World Bank, Harvard University Press, Boston

O'Riordan, T.; RAYNER, S. (1991): Risk Management for Global Environmental Change. Global Environmental Change 1 (2): 91 108

OECD (1995): The Life Cycle Approach: An Overview of Product/ Process Analysis. Technology and Environment, OECD/ $\mathrm{GD}(95) 118$, Paris

Owens, W. (1998): Life Cycle Impact Assessment: The Use of Subjective Judgements in Classification and Characterisation. Int J LCA 3 (1): $43-6$

PotTTNG, J.; HauschiLd, M. (1997): Predicted Environmental Impact and Expected Occurrence of Actual Environmental Impact. Part I: The Linear Nature of Environmental Impact from Emissions in Life Cycle Assessment. Int J LCA 2(3): 171-7; Part II: Spatia! Differentiation in Life-Cycle Assessment via the Site-Dependent Characterisation of Environmental Impact from Emissions. Int J LCA 2 (4)

Potting, J.; Schopp, W.; Blok, K.; Hauschlld, M. (1998): Site-dependent life-cycle impact assessment in acidification. Journal of Industrial Ecology $2(2): 63-87$

RAYNER, S. (1991): A Cultural Perspective on the Structure and Implementation of Global Environmental Agreements. Evaluation Review 15 (1): 75-102

RaYNER, ST. (1987): Risk and Relativism in Science for Policy. in Johnson B.B., Covello V.T. (Eds.), The Social and Cultural Construction of Risk, pp.5-23

Rayner, ST.; Cantor, R. (1987): How Fair is Safe Enough? The Cultural Approach to Societal Technology Choice. Risk Analysis 7 (1): $3-9$

SCHERINGer, M. (1999): Persistenz und Reichweite von Umweltchemikalien. Wiley-VCH, Weinheim

SCherInger, M.; BerG, M. (1994): Spatial and Temporal Range as Measures of Environmental Threat. Fresenius Envir Bull 3: 493-8

SCHMIDT-BlEEK, F. (1993): MIPS Re-Visited. Fresenius Envir Bull 2: 407-12

SChwarz, M.; Thompson, M. (1990): Divided we Stand; Redefining Politics, Technology and Social Choice. University of Pennsylvania Press

SETAC (1993): Guidelines for Life-Cycle Assessment: A 'Code of Practice'. Workshop Sesimbra, 31.3.-3.4.1993, Brussels

SteEN, B.; RydING, S.-O. (1992): Swedish Environmental Research Institute, Federation of Swedish Industries, The EPS Enviro-accounting Method. Göteborg

Thompson, M.; Ellis, R.; Wildavsky, A. (1990): Cultural Theory. Westriew Print, Boulder

Thompson, M.; RAYNer, St.; Cultural Discourses. in Rayner, St.; Malone, L. (Eds.) (1998): Human Choice and Climate Change. Vol.1, Batelle Press, Columbus Ohio

TimmermanN, P. (1986): Mythology and Surprise in the Sustainable Development of the Biosphere. in Clark, W.C.; Munn, R.E. (Eds.), Sustainable Development of the Biosphere. Cambridge University Press, Cambridge 
Udo de HAEs, H.A.; WrIsberg, N. (Eds.) (1997): Life Cycle Assessment: State-of-the-Art and Research Priorities. Results of LCANET, a Concerted Action in the Environment and Climate Programme (DG XII), LCA Documents, Volume 1, Eco-Informa Press, Bayreuth

Udo de Haes, H.A.; Jolliet, O.; Finnveden, G.; Hauschild, M.; KREWITT, W.; MULLER-WENK, R. (Eds.) (1999): Best available practice regarding impact categories and category indicators in Life Cycle Impact Assessment. Background document for the second working group on Life Cycle Impact Assessment of SETAC-Europe (WIA-2). Int.J.LCA 4 (2) 66-74/ 4 (3) 167-174

VOLKWEIN, ST.; KLOPFFER, W. (1996): The Valuation Step in LCA: Part I: General Principles. Int J LCA 1(1): 36-9

VROM (ed.) (1994): Policy document on products and the environ- ment. Ministry of Housing, Spatial Planning and the Environment (VROM), The Hague

Weber, O.; SCholz, R.W.; BülmanN, R.; Grasmuck, D. (1999): Risk Perception of heavy metal soil contamination and attitudes to decontamination strategies. UNS Working Paper 19, Natural and Social Science Interface, ETH Zurich

WHO (1947): The Constitution of the World Health Organization. WHO Chronical 1: 29, Geneva

WRISBERG, N.; GAMESON, T. (Eds.) (1998): CHAINET Definition Document, European Network on Chain Analysis for Environmental Decision Support. CML Leiden

Received: July 27th, 1999 Accepted: January 20th, 2000 Online-First: February 18 th, 2000

\section{Appendix 1: Introduction to Cultural Theory}

The anthropologist Mary Douglas has proposed a grid-group theory to help identify and compare ways of life (DougLAS, 1982; Dovglas et al., 1982). She argues that the variety of an individual's involvement in social life can be adequately captured by the two dimensions of sociality: group and grid. "Group refers to the extent to which an individual is incorporated into bounded units. The greater the incorporation, the more individual choice is subject to group determination. Grid denotes the degree to which an individual's life is circumscribed by externally imposed prescriptions. The more binding and extensive the scope of the prescriptions, the less of life that is open to individual negotiation." (cited from THOMPSON et al. (1990:5))

Each combination of the extremes of these two dimensions results in an archetype (synonym: cultural perspective). These four archetypes based on different characteristics of social relations are complemented by a fifth, called "autonomy", devoid of social interactions. This archetype is placed in the center of the grid and group dimensions as shown in Fig. 5, but in reality is meant to be in a third dimension where no social interactions occur at all.

A description of the five archetypes taken from Thompson et al. (1990:6f) is given below. It is essentially based on Douglas (1982:202ff).

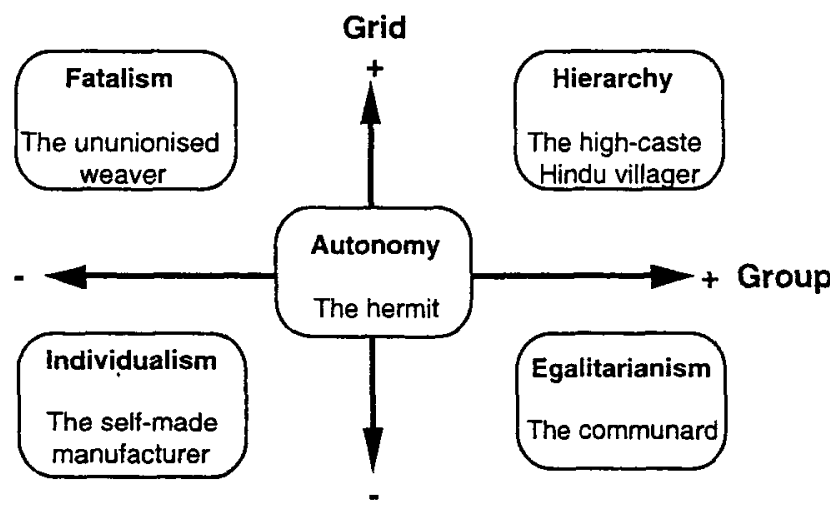

Fig. 5: Proposal for a constructed division of society into five cultura perspectives according to the grid-group theory (THOMPSON et al., 1990)
"Strong group boundaries coupled with minimal prescriptions produce social relations that are egalitarian. Because such groups lack (as a consequence of their low grid position) internal role differentiation, relations between group members are ambiguous. And since no individuals are granted the authority to exercise control over others by virtue of their position, internal conflicts are difficult to resolve. Individuals can exercise control over one another only by claiming to speak in the name of the group, hence the frequent resort to expulsion from the group in resolving intragroup differences. The drastic nature of these solutions, however, tends to drive disagreements underground, hence the presence of covert factions vying for control.

When an individual's social environment is characterised by strong group boundaries and binding prescriptions, the resulting social relations are hierarchical. Individuals in this social context are subject both to the control by other members in the group and to the demands of socially imposed roles. In contrast to egalitarianism, which has few means short of expulsion for controlling its members, hierarchy has an armoury of different solutions to internal conflicts, including up-grading, shifting sideways, downgrading, resegregating, redefining. The exercise of authority (and inequality more generally) is justified on the ground that different roles for different people enable people to live together more harmoniously than under alternative arrangements.

Individuals who are bound by neither group incorporation nor prescribed roles inhabit an individualistic social context. In such an environment all boundaries are provisional and subject to negotiation. Although the individualist is, by definition, relatively free from control by others, that does not mean the person is not engaged in exerting control over others. On the contrary, the individualist's success is often measured by the size of the following the person can command.

People who find themselves subject to binding prescriptions and are excluded from group membership exemplify the fatalistic way of life. Fatalists are controlled from without. Like the hierarchist, their sphere of individual autonomy is restricted. They may have little choice about how they spend their time, with whom they associate, what they wear or 
eat, where they live and work. Unlike hierarchists, however, fatalists are excluded from membership in the group responsible for making the decisions that rule their life.

For a few individuals there is a fifth possible way of life, one in which the individual withdraws from coercive or manipulative social involvement altogether. This is the way of life of the hermit, who escapes social control by refusing to control or to be controlled by others."

The grid-group theory has been further developed and named sociocultural viability theory and this in turn has been shortened to Cultural Theory (see, e.g., THOMPson et al., 1990; SCHWARZ et al., 1990; RAYNER, 1987/1991; RAYNER et al., 1987; O'RroRDan et al., 1991). Cultural perspectives are the viable combinations of cultural biases and social relations. Cultural bias refers to shared values and beliefs; social relations addresses the already introduced form of interpersonal relations. It is an important element of the theory that cultural bias and social relations condition each other without giving causal priority to one of them.

The condition of requisite variety means that the five cultural perspectives do not only compete for adherents but also require each other in order to be forced to demarcate oneself from the other perspectives. However, they are distributed unevenly and their shares change over time and place.

The definitions given so far may support the idea that all of us embody one and just one of these archetypes. This does not hold for at least two reasons: First, the archetypes are - as the name already suggests - extremists within a group. Most of us carry elements of all perspectives in us and at a given time just feel most comfortable in one of these social constructs, if at all. Second, Douglas et al. (1982) assumed that individuals try to organise themselves in such a manner that all spheres of their life belong to the same cultural perspective. But THOMPsON et al. (1990) acknowledge that the same individual may well change from an individualistic working sphere to an egalitarian family environment or/and a hierarchic religious group or sports activity. This change of spheres poses a major problem for empirical research with individuals that are out of their context or group. In short, the archetypes are to be considered at present as theoretical constructs that permit a comprehensive, sociologically shaped classification of decision makers. However, an individual decision maker may well switch between different perspectives due to situational constraints or exhibit a mixed profile.

One of the reasons to choose Cultural Theory (CT) for our purpose was that it is able to differentiate between the different archetypes with respect to the attribute category 'view of nature'. Thompson et al. (1990) have used the concept of the social construction of nature introduced by Holling (1977/ 1986) and Timmermann (1986) and linked it with CT.

Nature benign refers to the equilibrium-centered view in Fig. 6. It is represented by "a landscape with a bowl-shaped valley within which a ball moves in a way determined by its own acceleration and direction and by the forces exerted by the bowl and gravity. If the bowl was infinitely large, or events beyond its rim meaningless, this would be an example of global stability" (HoLLING, 1986:294). In such a world, trials and mistakes of any scale can be made, i.e., recovery is assured once the disturbance is removed. Nature ephemeral or the myth of instability can be seen as the obverse of the myth of nature benign. "In natural systems, the best example of this may be a simple closed predator-prey relationship - a proliferation of prey leads to a proliferation of predators who eventually consume all the prey and then starve to death" (TimMERMANN, 1986:439). Only if the ecosystems are treated with great care and the fragility of nature is respected can its complete collapse be prevented. Both nature perverseltolerant and nature resilient assume that multiple equilibrium states are possible or even necessary. In the case of nature perverse/ tolerant it is expecred that nature will show a continuous behaviour over a defined period as reaction to stressors. These periods end with sharp changes induced by internal dynamics or by exogenous events, at times large, at times small (Holunn, 1986:295). Nature resilient postulates not only multiple equilibria in a landscape. "The myth of resilience sees nature as nature naturing, i.e., nature actively alrering and responding in various ways to predictable or unpredictable stresses. This means that not only must one account for the internal structure of a system and its potentialities, but also the external context of chance and unpredictable impacts must be incorporated. This is because the system is presumed capable of some sort of adaptive memory, i.e., learning through historical time" (TIMMERMANN, 1986:444). Nature Resilient the 'hermit's myth' of nature - is not easy to visualise by means of a ball in a landscape (the landscape and the ball are moving) and for this reason is not shown in Fig. 6.

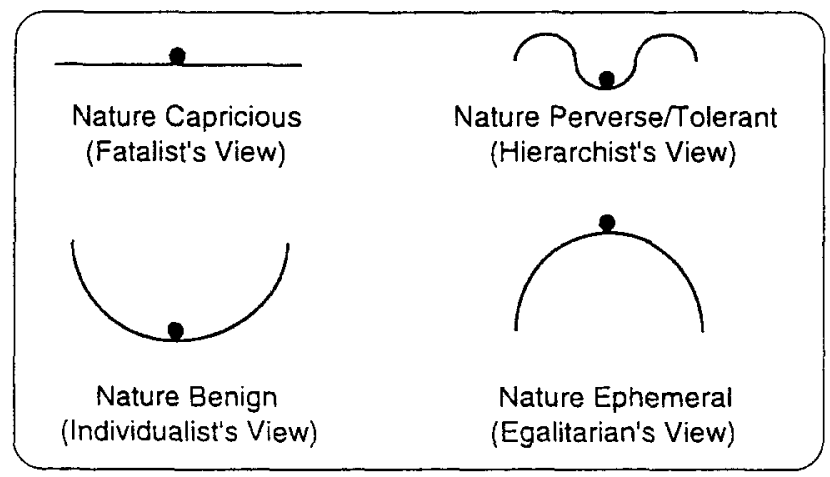

Fig. 6: The four primary myths of nature (derived from THOMPson et al., 1990). The rolling ball represents the state of nature, which is shifted by human activities to the left or the right or up and down the curved shapes which represent the system's behaviour (metaphor of a sphere rolling in a landscape).

Thompson et al. (1990) themselves developed a visualisation of the 'fatalist's view' that nature is unpredictable. They argue that "since fatalists seldom find themselves in charge of major national and international agencies, one of the five myths - Nature Capricious - was not fully elaborated by ecologists" (THoMpson et al., 1990:37).

All of these myths of nature may describe nature adequately at a given time and place and fail at a later observation or other place. However, it is important that individuals tend to have a biased perception, which makes that they tend to 
observe nature when it behaves according to their myth and remembering predominately only those situations which support their own bias.

Not all the predictions made here and in Table 1 (p. 164) are empirically tested and at least some of the attributes have been questioned by some studies. Validation is still outstanding but also difficult because not all of the elements are falsifiable and, e.g., it is not fully clear if surveys of individuals or only of focus groups are capable to validate the theory. This shortcoming is compensated, however, by CT's proven and successful applicability, the clear underlying theory, and the useful long list of attributes concerning world views and management styles. This makes it a useful heuristic to model the valuesphere in the context of LCA.

\section{Appendix 2: Damage Assessment}

Fig. 7 illustrates a proposal on how the environment can be represented by three safeguard subjects: human health, ecosystems quality, and resources. These three safeguard subjects were already suggested as areas of protection by SETAC (1993) and ISO (1997). Udo de Haes et al. (1999) added recently a fourth, the man-made environment. This extension is a good example of the normativity of such settings and the historical move in societal priorities. The EPS-method makes use of five safeguard subjects (STEEN et al., 1992) and a more intensive involvement of stakeholders will be necessary to find a consensual set of subjects. Besides defining the elements of the environment that have to be safeguarded, it is further necessary to define the changes in them that are seen as damages and those states of theirs that are to be considered as reference points.

Hofstetter (1998) suggests for human health a definition that is in line with WHO (1947): "Health is not only the absence of infirmity and disease but also the state of physical, mental and social well-being". Murray et al. (1996) have developed on behalf of WHO and Worldbank the approach of 'Disability Adjusted Life Years' (DALYs). According to this concept, premature deaths and all kinds of disabilities are considered as damages to human health. The before-mentioned authors have chosen as reference point the life-table of Japanese women. The concept allows add- ing up both life years lost and disability adjusted life years. The disability weights have been provided by internationally known health experts. Goedkoop et al. (1998) have provided analogous definitions and concepts for ecosystems quality and resources.

The normative selection of safeguard subjects and the definition of the changes that damage them is the precondition for the assessment of the direct and indirect damages due to environmental interventions. The impact pathway analysis (EXTERNE, 1995; KREwITT, et al. 1998) is used to model the causal relationships. In Fig. 8 the example of emissions is used to show how this approach adds additional insights to the models used for each substep. It is important to mention here that the arrows indicate the direction of the cause to the damage and the way the single models are linked with each other. However, the development and the design of the single models follows the opposite procedure, i.e., the relevant effects are identified after the normative description of the changes that are considered to be damages to the safeguard subjects. With the help of knowledge about the exposure response slopes, the relevant exposure pathways are identified and finally the link between exposure and emissions is established. Hofstetter (1998) provides detailed results for carcinogenic and respiratory effects due to chemicals. Frischknecht et al. (2000) add results for ionising

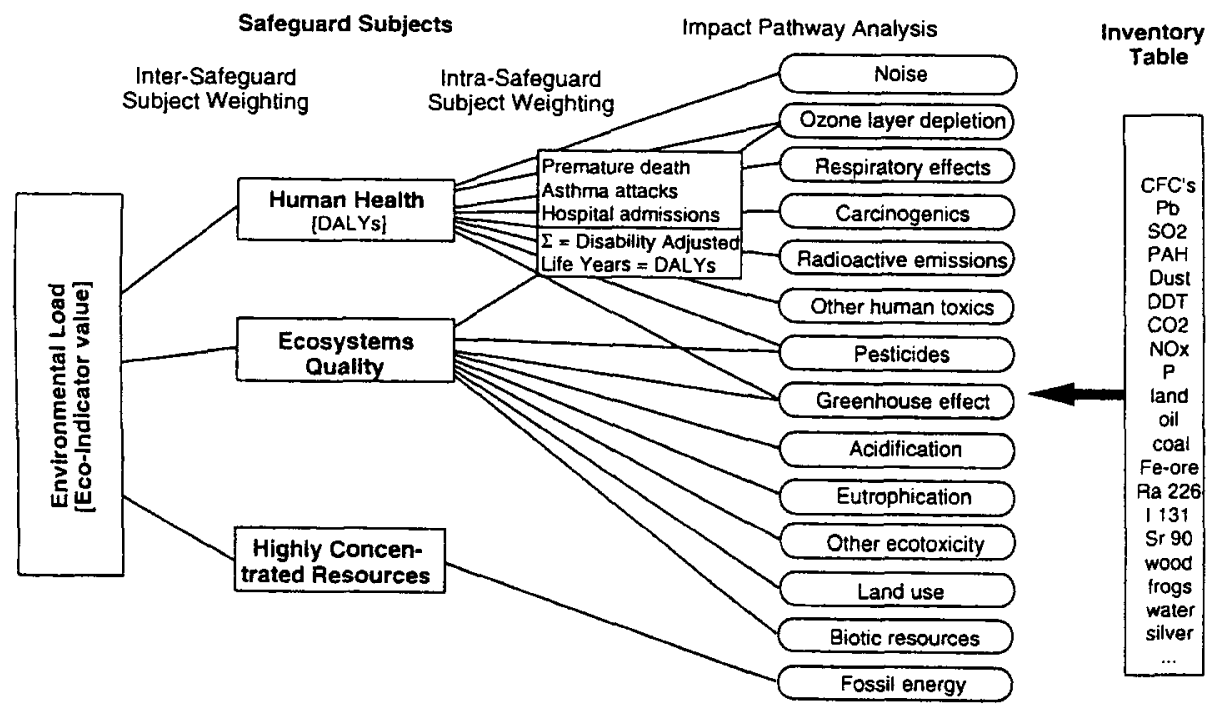

Fig. 7: Damage Assessment in LCIA by the prescription of safeguard subjects. The impact categories are only shown for illustrative reasons and are not constituting elements of the approach. 


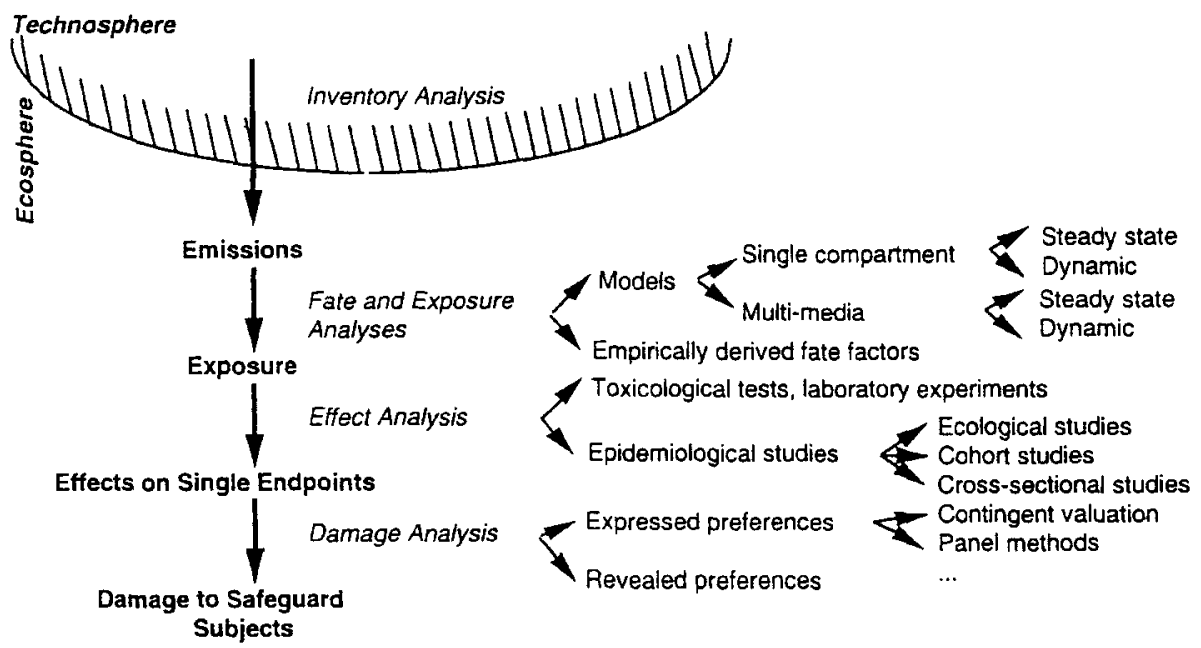

Fig. 8: General set-up of the impact pathway analysis within the ecosphere. The upper arrows for each level of analysis give examples for the causeoriented modelling and the lower arrows specify the descriptive modelling.

radiation and Goedkoop et al. (1999) for climate change, ozone depletion, ecotoxicity, acidification and eutrophication, land use and the use of energy and some metals. Hundreds of causal relationships between environmental interventions and damages to safeguard subjects have been quantified making use of much of the knowledge available in the respective sciences. Due to incomplete knowledge and the high natural variabiliry, modelling results can be described only as probability distributions instead of single numbers.

Value judgements are involved not only in the choice of safeguard subjects and the definition of damaging change but also when damage indicators are defined and causal chains have to be identified. Hofstetter (1998) discusses in detail the examples of age-weighting, i.e., whether years lived are equally valuable at all ages or not, and of the transferability of the results from toxicity experiments with animals to humans. Goedkoop et al. (1999) apply this concept throughout all the steps and for all damage categories including aspects such as the time horizon for the exposure modelling, the evidence needed to assume causal relationship, and the perspectives on the substitutability of fossil resources. These value judgements should be made in each case for the three cultural perspectives. This is where CT, the model of the valuesphere, is linked with the submodel of known damage within the ecosphere.

\section{Appendix 3: Proxy Indicator for Unknown Damage}

Modelling the unknown damage seems to be a contradiction in itself. Validating it will have to await at least until future generations can arrive at a judgement. Our ambition here is somewhat different, namely to develop a precautionary indicator to complement the damage indicators and to stand as proxy for the unavailable knowledge about the causal relationships between interventions and damages to safeguard subjects and for our lack of understanding of the overly complex ecosphere.

Some major reasons for this lack of understanding are:

- Safeguard subjects and ecosystem qualities, especially, are still ill-defined and it is basically impossible to differentiate between unavoidable evolutionary change and degradation. E.g., climate change clearly will alter ecosystems. But it is quite unclear whether this represents a decrease in ecosystem quality.

- Even apparently innocuous, small flows of persistent and accumulating substances emitted by the technosphere may lead in the long run to high concentrations provoking unexpected and new effects. This we already have experienced in the past with CFCs.

- Changes in the ecosphere have to be observed and iden- tified as damages; although scientists are keen to do so, their "eyes" (sensors) are not always at the right places. E.g., toxicity tests are performed under laboratory conditions and the endpoints are chosen in such a way that they can be measured by instruments. Changes in the test species' (social) behaviour or minor malformations will not appear in the charts.

- Human beings and other living organisms are not just exposed to a single substance but to cocktails of a large number of (globally distributed) substances. Nevertheless, our understanding of cause-effect relationships is still largely based on exposure to single substances.

Berg et al. (1994) and Scheringer (1999) suggest that such a proxy indicator is best defined on the level of exposure indicators. It is in the step from the level of exposure to damages where the incompleteness of modelling becomes obvious. Of course, a related uncertainty can be identified in the model of the technosphere where only business as usual and no major accidents are considered and where the analysts consider only measured emissions and assume that this covers all emissions, i.e., non-measured emissions are implicitly considered to be non-existent or irrelevant. How- 
ever, we are looking for a submodel of the ecosphere and consequently select the level of exposure for the definition of the proxy indicator.

A number of proxy indicators have been proposed and used in the past, e.g., market price, cumulated energy demand (IFIAS, 1974), MIPS (SCHMIDT-BLEEK, 1993), and spatial and temporal ranges (SCHERINGER et al., 1994). Only the last proposal starts at the level of exposure. Its foundation is largely based on equity principles, designed for the evaluation of new substances and quantified with two indicators.

Hofstetter (1998:113ff) has developed a new approach in order to make sure that the proxy indicator is appropriate for LCIA, complements the damage indicators and incorporates solutions to some of the four problems mentioned above. The proxy indicator basically considers the accumulative behaviour of a substance, which indirectly includes its persistency as well, and an experience factor to reflect the fact that our knowledge is in general lower for substances with which we have little experience. Given the availability of data and the aim of keeping the indicator simple, Hofstetter has constructed an indicator for our experience with a specific substance. Its numerator consists of the bioconcentration factor $(B C F)$ as an indicator for the accumulation behaviour. The denominator is the sum of total world-wide anthropogenic emissions plus the world-wide geogenic flows of this same substance $(B)$. Equation (1) shows that both highly bioconcentrating substances that are globally emitted in low quantities and xenobiotics will score higher than both non-accumulating substances or substances that are circulated in huge geogenic flows.

$U=\Sigma_{i}\left(I_{i} \cdot \frac{B C F_{i}}{B i}\right)$

where $U$ proxy indicator for unknown damage

$B C F i$ bioconcentration factor in fish for substance $i$

Ii environmental intervention $i$ per functional unit

$\mathrm{Bi} \quad$ world-wide anthropogenic emissions of substance $i$ plus world-wide geogenic flow which leads to concentration available to the biota $[\mathrm{kg} / \mathrm{a}]$

The bioconcentration factors were used for the substances studied by Hofstetter (1998:129). But the accumulation indicator has still to be worked out for geo-accumulating substances, for the de-cumulation of resources, and for the alteration of habitats.

\section{Appendix 4: Manageability of Damages}

The damage indicators modelled in Appendix 2 (p. 172) quantify the integrated damages due to the marginal change of environmental interventions. Consequently, they do not include attributes such as the expected effort to return the damages to an acceptable level or the possibility of administrative solutions. Both attributes have been considered as relevant by a stakeholder panel (KORTMAN et al., 1994). Lindeijer (1994) was the first to suggest to consider in LCIA the dynamics of harm in addition to its magnitude and seriousness. Unfortunately, he provided no operationalisation of his proposal. Each of the following arguments is transformed into a combined indicator that will finally constitute the manageability factor:

- Decision makers will give higher priority to an environmental problem if the damage caused by it is difficult to correct and undo. Therefore, the ease of damage reduction is chosen as a first indicator.

- Decision makers may tend to give higher priority to environmental problems if they have a higher excess of long-term policy or sustainability targets. A high target damage excess factor implies an uncertain but probably strong demand for changes in behaviour, technique and legislation. It is this uncertainty that makes this indicator relevant.

- Thirdly, the control over risks is an important aspect of manageability. It will be indicated by the success of regulation. A problem will be judged less relevant if it is well known and the regulations already implemented will allow meeting the long-term policy targets than problems that remain uncontrolled.
Hofstetter (1998) has operationalised all three indicators and applied them to two examples:

- The indicator for the ease of damage reduction is built on knowledge about the possibilities to reduce damages due to emissions by assuming that a fixed amount of financial and legislative means is available overall. The achievable reduction may differ very much depending on the character of the environmental problems. The maximally available financial and legislative means depend on the cultural perspective. While individualists are hesitant to agree with additional laws or decrees, egalitarians and hierarchists would make use of these instruments. Hierarchists also believe in research and control and therefore are willing to spend more financial resources on them than egalitarians and individualists do. It is estimated that research for cancer suppressing agents, for improved methods for early tumour detection, for intensified cancer screening programs, and for the legislative reduction of synergistically acting risk factors such as smoking could reduce the damages due to environmental carcinogens by 20 to $50 \%$, depending on the amount of additional expenditures and on the strictness of new laws.

- The excess of policy targets is quantified by dividing the damage at a reference year with the damage agreed on to be the long-term policy target or to represent a sustainable level. In the case of environmental carcinogenesis, it is estimated that the present level is 200 premature deaths per year per million inhabitants and many long-term policies aim to reduce single risks to 1 premature death per year per million inhabitants. 


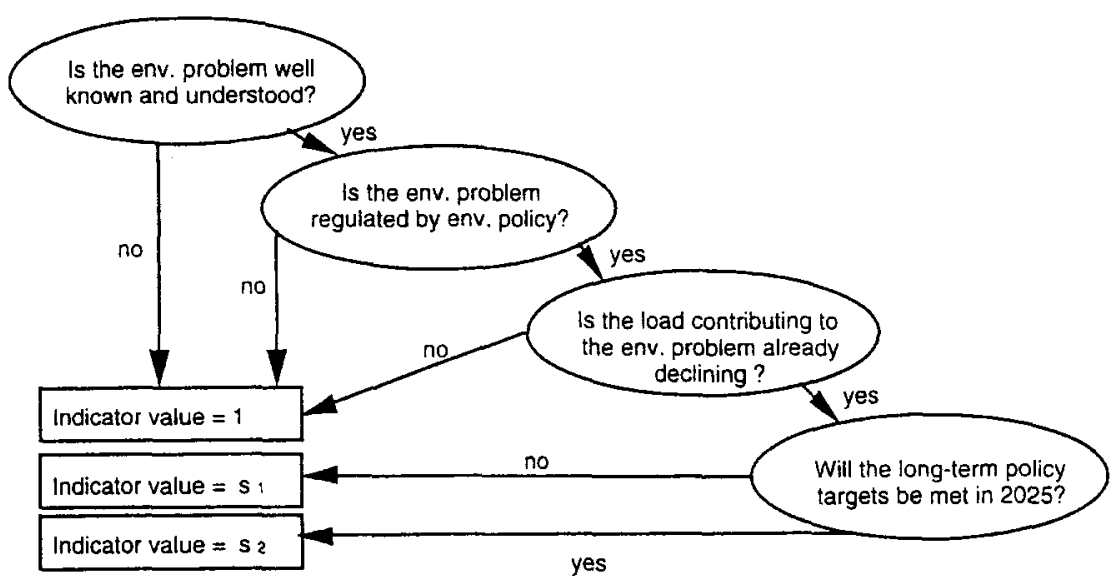

Fig. 9: Decision tree to define a indicator value for regulation success per environmental problem

- Fig. 9 provides a scheme to derive an indicator for what we call the regulatory success. The uneven importance given to this indicator by the three cultural perspectives is reflected in the parameters $s 1$ and $s 2$. In the case of environmental carcinogenesis, the problem is well known and partly understood. Many regulations limit the emissions or use of carcinogenic substances, and the emissions of substances such as benzene, poly-aromatic hydrocarbons or heavy metals are indeed declining in the industrial countries. However, the mentioned long-term target will not be met by following the present regulations, partly because the aim is very ambitious and partly because of the high persistency of some carcinogenics and the long latency time between today's exposure and the expected effects. The indicator value $s 1$ is therefore chosen following the diagram in Fig. 9, which is presently translated into adjustment factors of 0.8 for both the egalitarian and the hierarchic perspectives and of 0.9 for individualists (lower importance of long-term planning).

The exact composition of the manageability factor is provided by Equations (2) and (3). Hofstetter (1998:145) provides first estimates for the parameters. However, empirical work with decision makers will be necessary to validate them.

$$
\begin{aligned}
& m_{p, c}=R_{p, c} \cdot X_{p, c}{ }^{g c} \cdot S_{p, c}= \\
& m_{p, c}=\left(\begin{array}{ll}
\left.1-\text { relative reduction of } D_{p} \text { at } E_{c} \cdot f\right) \cdot\left(\frac{N_{p}}{T^{s c}} .\right. \\
\left(1 \text { or } 51_{i} \text { or } s 2_{c}\right\}
\end{array}\right. \\
& \text { with } m_{p}
\end{aligned}
$$$$
\text { with } m_{p, c} \quad \text { manageability factor [-] }
$$

$$
R_{p, c}^{p, c} \quad \text { indicator for the ease of damage reduction [-] }
$$$$
X_{p, c}^{p, c} \quad \text { indicator for the excess of long-term policy }
$$
targets[-]

$S_{p, c} \quad$ indicator for the success of regulation [-]

$D_{p, c} \quad$ outcome of the damage assessment for human or ecological health measured in the respective damage units

$E_{c} \quad$ additional unit effort in financial and legislative terms

$f \quad$ consideration factor dependent on the modelling assumptions in the damage assessment $N_{p} \quad$ impact due to present environmental interventions contributing to environmental problem $p$ $T_{p} \quad$ target level for the environmental problem $p$ $g_{c} \quad$ cultural perspective dependent exponent $s 1_{c}, s 2_{c}$ parameters for the regulatory success factor $p \quad$ index for environmental problem

c index for the three cultural perspectives ('individualists', 'egalitarians' and 'hierarchists')

\section{LCA-Online Editions: Three modifications are available:}

1. The LCA databank of published articles which can be called up with the aid of keywords and has been active since 1998 (http://www.scientificjournals.com/db). Parallel to the preparations for printing, the databank is actualized.

2. The LCA Online-First forum with the available articles which have already been accepted for publication but not yet published in the printed journal (http://www.scientificjournals.com/onlinefirst). Online-First is updated immediately following the final acceptance of the articles and the completion of corrections by the author.

3. The LCA Web Editions provide access to the articles which have been published since 1998 by way of the Table of Contents of every individual new issue (http://www.scientificjournals.com/db/webEditions.htm). This online version is identical with the printed issue. Parallel to the preparations for printing, the web editions are actualized.

The three Online Editions (up to and including the abstracts) are available to anyone who is interested. A password (PW) must be entered as soon as the full article is to be called up. The $P W$ is the six-digit order number.

Library access is available via the IP address.

Please also note the LCA Homepage (http://www.scientificiournals.com/lca). This site is accessible to anyone and provides full information about the journal itself, as well as about new trends and developments. In addition, the Editorials, Letters, Books/Reviews, Conference Reports are available here. This site also undergoes continuous actualizations. 